\title{
Care Strategies for Schizophrenic Patients in a Transcultural Comparison
}

\author{
Detlev von Zerssen, Carlos A. León, Hans-Jürgen Möller, Hans-Ulrich Wittchen, Hildegard \\ Pfister, and Norman Sartorius
}

This study was conducted in order to test the hypothesis derived from the International Pilot Study of Schizophrenia (IPSS) that the existence of extended families in developing countries contributes to the more favorable course and outcome of schizophrenia in these countries in comparison with industrial countries. For this purpose, we compared data from the 5- and 10-year follow-up obtained within the IPSS at Cali, Colombia with data from two 5 to 8-year follow-up studies of former schizophrenic inpatients of the Max Planck Institute of Psychiatry (MPIP) in Munich, FRG. Although, in Cali, schizophrenics are hospitalized and treated with drugs only during acute episodes of the psychosis and no facilities exist for long-term treatment, the psychopathological outcome was, on the whole, not worse than in Munich. Furthermore, the duration of hospitalization during the follow-up period was much lower at Cali and a significantly lower number of Colombian than of German patients was not separated from their families. However, contrary to the hypothesis, family size did not predict course and outcome at both centers.

Following the introduction of neuroleptic drugs into the treatment of schizophrenia, new standards for an optimal care of schizophrenic patients have been developed. Care strategies comprise inpatient and outpatient facilities for continuous drug treatment over months and years, as well as supportive psychotherapy, social skills training, and rehabilitative measures. It is generally acknowledged that these standards are only met in a few industrial countries and even there at only a few places. Among them are London in the UK and Aarhus in Denmark. At the other extreme, there are care systems in developing countries that may offer drug treatment only during acute stages of a psychosis when the patient is referred to one of the few psychiatric hospitals; outpatient facilities are rare or virtually lacking. For these reasons, it should be expected that course and outcome of schizophrenia are much worse in such countries compared with industrial countries that already possess a highly developed psychiatric care system, as is particularly the case in parts of the UK and Denmark. Indeed, in areas of developing countries with no psychiatric care at all, such as in the rural districts of Laos, schizophrenic psychoses seem to take an unfavorable deteriorating course. ${ }^{1}$

Amazingly, however, results of the International Pilot Study of Schizophrenia (IPSS) - a transcultural multicenter study on psychopathology, course, and outcome of schizophrenic and other psychoses - which was organized by the World Health Organization (WH0), ${ }^{2}$ point to the opposite direction: psychopathology at intake to a psychiatric hospital was similar at the nine centers participating in the study. Yet, course and outcome were most favorable in two centers of developing countries with the relatively poorest economic development and a correspondingly low level of the psychiatric care system, namely Ibadan in Nigeria and Agra in India. They were worst in the two centers of industrial countries where modern care strategies have reached the relatively highest level, i.e., London, UK and Aarhus, Denmark. ${ }^{3}$ Selection bias is probably not a sufficient explanation of these unexpected findings. ${ }^{4}$ They call for a more thorough analysis of sociocultural differences between the countries under comparison and a search for mechanisms that may have a positive impact on course and outcome of psychoses in some developing countries. These mechanisms appear to be lacking or impaired in highly industrialized countries. The authors of the IPSS follow-up 
hypothesized that the existence of extended families may account for the more favorable course and outcome of psychoses in developing countries. ${ }^{3}$

We have therefore undertaken a comparison of course and outcome of schizophrenia at two sites with marked differences in economic development, average family size, and level of psychiatric care, but with a more similar religious and cultural background than Ibadan and Agra on the one hand and London and Aarhus on the other. For the two centers, criteria of course and outcome were also separately related to family size in order to check the influence of the latter on course and outcome, independently of the whole social context in different cultures. The two centers were Cali in Colombia, one of the nine centers of the IPSS, and Munich in the FRG, where two 5- to 8-year follow-up studies of schizophrenics and other former inpatients of the Max Planck Institute of Psychiatry (MPIP) had been performed independently of the IPSS. ${ }^{5,6}$ The results regarding schizophrenics in the first of these two MPIP studies ${ }^{5}$ had been compared with results of the US center of the IPSS in Washington, DC, ${ }^{7-9}$ and found to be remarkably similar to them. ${ }^{5,10}$

Data from the two Munich follow-up studies were combined and then compared with data of the 5-year follow-up of the Cali cohort because of the similarity of the follow-up intervals. In addition, the 10-year follow-up in Cali ${ }^{11}$ was also taken into account. The comparison was restricted to samples of similar distribution with respect to age and gender and to variables that were either assessed in a similar manner or could be made comparable by special methods of data processing.

\section{Methods}

\section{Subjects}

A total of 140 subjects, 70 from each center, were selected for the present analysis. Selection criteria were definite diagnosis of schizophrenia (International Classification of Diseases [ICD]-8, no. 295), excluding the subgroup of schizoaffective psychosis (no. 295.7); same proportion of males $(n=42)$ and females $(n=28)$; and age range 15 to 39 years. Because of a significant difference between the two samples in age and in the percentage of first admissions (see below), comparisons, which were most pertinent to the problems of this study, were repeated with subsamples of a more similar age distribution, admitted to the hospital during their first psychotic episode and investigated within 10 days after intake.

According to the Research Diagnostic Criteria (RDC), ${ }^{12}$ seven of the 70 MPIP patients were diagnosed as suffering from a schizoaffective psychosis. Despite the exclusion of ICD no. 295.7, this is probably due to the fact that the course of the disorder is not taken into account in the RDC as is the case at the MPIP, where this diagnosis follows Kasanin's ${ }^{13}$ original description of the disorder. ${ }^{14}$ In another case, the RCD diagnosis was that of a psychotic depression. However, at follow-up, the lifetime diagnosis was that of schizophrenia according to the ICD-9, as well as to the RDC. In the other 62 cases, the index diagnosis of a schizophrenic psychosis was concordant with the RDC. For the Colombian sample, no RDC diagnoses are available, but the inclusion of patients in the study was based on operational criteria. $^{2}$ 
Apart from gender and age, several demographic and illness-related variables had been recorded. The following (Table 1) were used for the comparison because they could be expected to have predictive value for course and outcome of a schizophrenic psychosis according to earlier follow-up investigations ${ }^{5,7-9,15-19}$ or according to the above-mentioned hypothesis derived from the IPSS follow-up.

Scores on rating scales of the mental status at follow-up in relation to those obtained at index investigation served as outcome criteria for a direct comparison of psychopathology between the two samples. These scales were composed of 40 of the 90 items of the Inpatient Multidimensional Psychiatric Scale (IMPS) ${ }^{20}$ which was used in the Munich studies, and of 44 of the 129 units of analysis (UA) of an earlier version of the Present State Examination $(\mathrm{PSE})^{2,21}$ which was applied within the IPSS. The two subsets of items/UA were similar in content and formed five similar factors in both samples. The scales, in which some of the items/UA were combined to only one variable (see Appendix), were derived from these factors. A good outcome was defined by scale values at follow-up only in the first quartile of those obtained at index investigation; the criterion for a bad outcome was at least one value above the median, i.e., the third or fourth quartiles of the index values. At least one value in the second, but none in the third or fourth quartiles indicated an intermediate outcome according to our definition.

In addition, the total number of positive scores on all 90 IMPS items or on the 129 UA of the PSE served as graded outcome criteria within the two centers (Table 2). However, the latter criterion (no. 3 in Table 2) was not used for a comparison between the centers because of the different numbers of items and UA, respectively, in the two rating instruments. Likewise, a 5point global rating of psychopathology at follow-up was used as a further outcome measure for the Cali sample only, and the score on the 100-point Global Assessment Scale (GAS) ${ }^{22}$ served as a further outcome criterion for the Munich sample (no. 4 in Table 2). It should be noted that a higher score on this scale indicates a higher level of psychosocial functioning, i.e., a better outcome, whereas higher scores on the global scale used in the Cali sample reflect a higher degree of psychopathology, i.e., a worse outcome. As the information about the patients' social situation at the 5-year follow-up at Cali was scarce, we only analyzed one social outcome criterion for the Munich sample, which seemed most relevant with respect to the patients' integration into the family, i.e., whether he/she was living alone/in home care or together with at least one family member. A criterion for the course of the disorder during the follow-up period at both centers was the percentage of time spent in a psychiatric hospital (Table 2).

\section{Results}

\section{Index Investigation}

As expected, a significant difference in the number of family members living together with the patients in Munich and Cali, respectively, was ascertained, with a higher number in the Colombian sample. For this reason, we dichotomized the numbers of subjects in the patients' home differently for the Munich and the Cali data (Table 1) in order to obtain a balanced proportion of smaller and larger households at each center, when checking the predictive value of family size within the two samples. Nevertheless, the difference between the two centers remained still significant (Table 3). However, other expected differences in social 
variables between the two samples, a lower educational and occupational level at Cali, were masked by applying different criteria for the respective dichotomies in the two samples (Table 1). Not predicted was a significant difference in sexual partnership due to a lower number of stable relationships of this kind within the Munich sample (Table 3). The aforementioned difference in the rate of first admissions among the samples, which is highly significant (Table 3), is probably responsible for the significant difference in age between the samples, whereas an almost significant difference in the percentage of unemployed subjects (Table 3) is rather a reflection of a general difference in the unemployment rate in Colombia (1973, $13.4 \%)$ and the FRG (1973, 1.2\%). The difference is probably even more pronounced with respect to the cities Cali (no data available) and Munich (1973, 0.7\%).

At index investigations, the German patients displayed a much higher degree of catatonic symptoms (at intake) than the Colombian patients who exceeded the German sample-not to the same degree but nevertheless significantly-in hostility (Fig 1). Values on the other scales are rather similar in the two samples.

\section{Follow-up}

At follow-up, the scores on all five scales have dropped significantly at both centers (Fig 1). However, the Munich sample still receives higher values with respect to catatonic symptoms. The other scales reach similar values in the two samples.

The total score of all 90 IMPS items and of the 129 UA from the PSE indicates the same general tendency toward improvement of the patients' psychopathology at follow-up, as is the case with the subscores based on combinations of selected items from the two rating instruments.

As indicated above, a direct comparison between the two samples is only feasible with respect to one of the three outcome criteria, i.e., the classification according to the newly constructed scales of psychopathology, and the one criterion of course, i.e., the percentage of the followup period spent in psychiatric hospitals. There are significant differences between the two samples in both these criteria of course and outcome, however, in quite different ways: In the Munich sample, an intermediate psychopathological outcome is far more often observed than in Cali, whereas the proportion of a favorable to an unfavorable outcome is not markedly different at the two centers (Table 4); this means that the outcome of the psychosis in the Colombian sample is more often either good or bad, but rarely in between compared with the outcome in the German sample. An even more striking difference is found with respect to the hospitalization rates: Whereas in the Cali sample all patients spent less than $10 \%$ of the follow-up period in a psychiatric hospital, the respective time varied up to well over $90 \%$ in the Munich sample. Since this finding is crucial from a practical as well as from a theoretical point of view, the relationships were also analyzed in the subsamples of patients admitted for the first time to a psychiatric hospital and similar in the distribution of gender and age in Munich ( $\mathrm{n}=33$ ) and Cali $(\mathrm{n}=30)$. As can be seen in Table 5, the result is in line with that obtained in the larger samples ( $\mathrm{n}=70$ each): almost half of the patients at both centers were hospitalized for at least up to $2 \%$ of the follow-up period; however, one third of the Munich sample and not a single case of the Cali sample spent more than $7 \%$ in a psychiatric hospital; in Munich, three of the patients were hospitalized for more than $80 \%$ of the time.

Furthermore, many of those who were not hospitalized were separated from their families at follow-up. The proportion of the patients living either alone or in a home for psychiatric patients to those living together with at least one family member had significantly increased during the follow-up period in the Munich sample (Table 6). In the Cali sample, no 
comparable information is available for the 5-year follow-up. However, even after 10 years, there is no similar increase of Colombian patients who were living isolated from their families.

\section{Prediction of Course and Outcome}

A pertinent question of our comparative data analysis refers to the predictive value of the patients' living situation to course and outcome of their psychoses. Amazingly, there are only a few predictors of course and outcome at both centers, and the number of family members living together with the patients at intake is not among them. The respective correlation coefficients are almost zero; this means that there is apparently no systematic influence of the family size on course and outcome. In view of the high number of correlations among predictors and criteria (44 each at the two centers), the number of correlations reaching a conventional level of statistical significance is too small for a valid interpretation of the respective relationships. Nonetheless, it seems remarkable that only social variables, not variables of the illness (younger versus higher age at onset, insidious versus acute onset, relapse versus first episode) reached a critical P value of at least 5\%. In Munich, the lack of a constant sexual partnership and, in Cali, being unmarried and, contrary to our expectation, having reached a higher educational level are the only variables-out of a set of 11 potential predictors-that correlate significantly with one of the four criteria of course and outcome in the direction of a poor prognosis as high as above .30 .

\section{Discussion}

Our comparison between follow-up data from Cali, Colombia and Munich, FRG has shown that the size of a family with which a schizophrenic patient has been living before index admission has no predictive value for course and outcome of the psychosis. Rather, the social advantage of schizophrenics in developing countries seems to be due to the fact that they are not so easily separated from their natural social environment as are psychotic patients in highly industrialized countries, such as the UK, Denmark, and the FRG. The present analysis clearly indicates the higher degree of the patients' isolation from their families in Germany compared with Colombia: the patients from Munich spent up to more than $90 \%$ of the followup period of 5 to 8 years in a psychiatric hospital. Although the total number of patients from Cali who were hospitalized during a 5-year period was similar to the respective number of the German sample (almost 50\% spent at least up to $2 \%$ of the time in a psychiatric hospital), the total time in hospital at Cab was always less than $10 \%$ of the follow-up period. Furthermore, even 10 years after index investigation, the Colombian patients had not lost a place in their families, as often as was the case after 5 to 8 years in the German sample. Here, many of the patients who had lived together with at least one family member before the index admission were now living alone or in a home for psychiatric patients when out of hospital.

Although the German patients received much more psychiatric treatment not only as inpatients, but also on an outpatient basis, they did not fare better than the Colombian patients at follow-up from a psychopathological point of view. The outcome of their psychoses was more often intermediate. whereas at Cali the outcome tended to be either good or bad according to our classification of the psychopathological state at follow-up. This difference is difficult to interpret. Possibly, it is caused by the higher usage of neuroleptic drugs in the Munich sample by which a basically psychotic state may have been masked and a nonpsychotic state may have been colored by side effects of the drugs. However, for our project, it is more important to note that the psychopathological state at follow-up compared with the state at index investigation is not clearly better for the German patients despite the 
much more intensive inpatient and outpatient care in and around the city of Munich than in a Colombian city such as Cali.

It has to be considered in this context that there were some differences in the psychopathological states of the German and the Colombian patients already at index investigation, of which the higher degree of catatonic symptoms in the Munich sample was the most prominent one. This difference may reflect a more severe psychopathological state of the Munich than of the Cali patients. The reason for it might be the fact that the rating of psychopathology was performed right after the patients' admission to the MPIP, whereas in Cali the index investigation often took place at a later point in time after intake when the psychotic symptomatology had already responded to drug treatment. Another reason might be that many psychotics in Munich are primarily treated by psychiatrists in free practice and are referred to one of the psychiatric hospitals only when the psychosis is too severe for outpatient treatment. However, at follow-up when the psychotic symptomatology had, on average, markedly improved in both samples, the German patients still displayed significantly more catatonic symptoms than the Colombian patients. Therefore, the possibility of a transcultural difference in the psychopathology of schizophrenia has to be taken into account.

Finally, it should be mentioned that not only the size of the family with which the patients had lived before their index admission had no predictive value for course and outcome of the psychosis, but that also most of the other potential predictors (according to the literature) did not show a significant relationship to the four criteria of course and outcome. It seems remarkable, though, that the only variables reaching correlation coefficients of above .30 to one of these criteria were indicators of social status: educational level (Cali), marital status (Cali), and a stable sexual relationship (Munich). A tendency toward a higher hospitalization rate in unmarried Colombian patients may point to the stabilizing effect of marriage. In the FRG, any kind of a stable sexual relationship predicted a higher level of psychosocial functioning at follow-up. Both these relations point out the importance of the patient's social integration for course and outcome of a schizophrenic psychosis.

The relationship of a higher educational level to the degree of psychopathology at follow-up in the Colombian sample was unexpected, but it was confirmed in the 10 -year follow-up. ${ }^{11}$ It is also supported by the as yet unpublished results of the 2- and 5-year follow-up within the Multicenter Collaborative Study of Factors Associated with the Course and Outcome of Schizophrenia in three Indian Centers (Final Report to the Indian Council of Medical Research, 1988). This may hint to the stress of a higher level of professional aspiration for patients whose capacity for intellectually more demanding and socially more competitive work is often impaired to some degree. It seems possible that course and outcome of schizophrenia are generally more favorable in a less complex social environment with simple tasks for the individual, which can be fulfilled even in a residual state after a psychotic breakdown. To quote Shepherd et $\mathrm{al}^{19}$ : "The environment to which the patient returns in developing countries is ... likely to be less demanding, both in the family, where lower expectations lead to greater tolerance, and socially, ... where status does not depend to such a large extent on clearly demarcated employment.”

The main results of the study, however, concern the differences in the hospitalization rate and in the degree of family integration during the course of the psychosis in an industrial and a developing country. They challenge the view that a highly developed professional care system is the best guarantee for improving the long-term course of schizophrenia. Rather, the patients' integration in a natural social environment and the restriction of medical interventions to an indispensable degree may be an optimal care strategy. This strategy is 
easier to realize in developing countries where the family structure is, on the whole, more intact than in industrialized countries with high divorce rates and a tendency to isolate the elderly and the sick from their families. All the more should attempts towards social integration of schizophrenics ${ }^{23-25}$ be emphasized in the care systems of highly developed countries.

Table 1. Potential Predictors for Course and Outcome of lliness

\begin{tabular}{|c|c|c|c|}
\hline No. & Designation & Categ & ories \\
\hline 1 & Gender & Mole & Femole \\
\hline 2 & Age & $\leq 24$ & $>24$ \\
\hline 3 & Crvil status & Unmarried & Married \\
\hline 4 & Educational level & $\begin{array}{l}\text { High school (Munich) or elemen- } \\
\text { tary school (Cali) }\end{array}$ & $\begin{array}{l}\text { Final high school exam (Munich) } \\
\text { or above elementary school } \\
\text { level (Cali) }\end{array}$ \\
\hline 5 & Employment status & Unemployed & Employed \\
\hline 6 & Occupational level & Low/middle level & Upper level \\
\hline 7 & Housing situation & $\begin{array}{l}\text { Home care, living alone or in a } \\
\text { small family (Munich up to } 2 \text {, } \\
\text { Cali up to } 3 \text { pereone) }\end{array}$ & Larger families \\
\hline 8 & Partnership & None or not stable & Stable \\
\hline 9 & Age at onset & $\leq 24$ & $>24$ \\
\hline 10 & Type of onset & Insidious & Acute \\
\hline 11 & Episode of disease & Relapse & First episode \\
\hline
\end{tabular}

Table 2. Criteris of Couree and Outeome

\begin{tabular}{|c|c|c|}
\hline No. & Designation & Scaling \\
\hline 1 & Duration of hospitalization & $\begin{array}{l}\text { Time in hospital during the follow-up } \\
\text { period in percent }\end{array}$ \\
\hline 2 & Scales of psychopathological factors & $\begin{array}{l}\text { 3-point scale (favorable, intermediate, } \\
\text { unfavorable) according to the corre- } \\
\text { sponding distribution of values at in- } \\
\text { dex investigation }\end{array}$ \\
\hline 3 & $\begin{array}{l}\text { IMPS items (Munich) or UA of the PSE } \\
\text { (Cali) }\end{array}$ & $\begin{array}{l}\text { Sum scure of all } 90 \text { dichotonized items. } \\
\text { respectively, } 129 \text { UA }\end{array}$ \\
\hline 4 & $\begin{array}{l}\text { GAS (Munich) or global assessment of } \\
\text { symptome (Cain) }\end{array}$ & $\begin{array}{l}\text { 100-point score for the GAS }(100= \\
\text { optimal functional state) or } 4 \text {-point } \\
\text { score ( } 4 \text { - severe symptoms) }\end{array}$ \\
\hline
\end{tabular}

Table 3. Comparison of 11 Predictors for the Patients From Munich $(n=70)$ and Cali $(n-70)$

\begin{tabular}{|c|c|c|c|c|c|c|}
\hline No. & Predictor & Category & Munich & Cali & $x^{2}$ & $P(\%)$ \\
\hline \multirow[t]{2}{*}{1} & Gender & Malvs & 42 & 42 & 0.03 & 80.30 \\
\hline & & Female & 28 & 28 & & \\
\hline \multirow[t]{2}{*}{2} & Age & $\leq 24 \mathrm{yr}$ & 26 & 40 & 4.84 & $2.77 \dagger$ \\
\hline & & $>24 \mathrm{\gamma r}$ & 44 & 30 & & \\
\hline \multirow[t]{2}{*}{3} & Civil status & Unmarried & 60 & 53 & 1.65 & 19.87 \\
\hline & & Merried & 10 & 17 & & \\
\hline \multirow[t]{2}{*}{4} & Educational level & (Under) average & 51 & 50 & 0.18 & 66.76 \\
\hline & & Above average & 16 & 20 & & \\
\hline \multirow[t]{2}{*}{5} & Employment status & Unemployed & 17 & 28 & 3.27 & $7.03^{*}$ \\
\hline & & Employed & 53 & 42 & & \\
\hline \multirow[t]{2}{*}{6} & Occupational level & Lower $/ \mathrm{midale}$ & 47 & 46 & 0.03 & 85.87 \\
\hline & & Upper & 23 & 25 & & \\
\hline \multirow[t]{2}{*}{7} & Housing situation & Alone/home/small family & 38 & 16 & 13.29 & $0.03 \ddagger$ \\
\hline & & Larger family & 32 & 54 & & \\
\hline \multirow[t]{2}{*}{8} & Partnership & No stable partnership & 41 & 28 & 4.49 & $3.40 \dagger$ \\
\hline & & Stable partnership & 28 & 42 & & \\
\hline \multirow[t]{2}{*}{9} & Age at onset & $\leqslant 24 \mathrm{yr}$ & 50 & 43 & 2.16 & 14.13 \\
\hline & & $>24 \mathrm{yr}$ & 17 & 27 & & \\
\hline \multirow[t]{2}{*}{10} & Type of anset & insidious & 27 & 36 & 1.65 & 19.85 \\
\hline & & Acute & 42 & 34 & & \\
\hline \multirow[t]{2}{*}{11} & Episode of disease & Relapse & 33 & 4 & 28.80 & $0.00 t$ \\
\hline & & First episode & 37 & 66 & & \\
\hline
\end{tabular}

NOTE. Predictors 4, 6, and 7 dichotomized differently according to the distributions at the two centers.

$\bullet P<.10 ; \uparrow P<.05 ; \ddagger P<, 001$. 
Table 4. Comparison of Outcome Assessment After 5 (to 8) Years of Patients From Munich $(n-66)$ and Cali $(n-70)$ With the Aid of Newly Construeted Scales of Psychopathology Derived From IMPS/PSE

\begin{tabular}{|c|c|c|c|}
\hline Outcome & Munich & Cali & $\Sigma$ \\
\hline Faunrable & 17 & 30 & 47 \\
\hline Intermediate & 25 & 8 & 33 \\
\hline Unfavorable & 24 & 32 & 56 \\
\hline $\mathbf{z}$ & 66 & 70 & 136 \\
\hline
\end{tabular}

NOTE. $\chi^{2}=13.39 ; d f=2 ; P=.12 \%$ (two-tailed).

Table 5. Percentage of Schizophrenic Patients Hospitalized for the First Time at Index Investigation Who Had Been in Hospital for Longer Than a Defined Period of Time During Follow-up

\begin{tabular}{lcc}
\hline & Munich $(\mathrm{n}-33)$ & Cali in -30$)$ \\
\hline At least up to $2 \%$ of the time & $48.5 \%$ & $46.7 \%$ \\
At lesst up to $7 \%$ of the time & $33.3 \%$ & - \\
At least up to $10 \%$ of the time & $27.3 \%$ & - \\
At least up to $20 \%$ of the time & $21.2 \%$ & - \\
Up to $80 \%$ of the time & $9.1 \%$ & \\
\hline
\end{tabular}

Teble 6. Association Between the Housing Situation at Index Investigation and Follow-up for the Munich Sample $(n-70)$

\begin{tabular}{lcccc}
\hline & \multicolumn{3}{c}{ Follow-up } & \\
\cline { 2 - 4 } \multicolumn{1}{c}{ Index Investigation } & $\begin{array}{c}\text { Living Alone or } \\
\text { in Home Care }\end{array}$ & $\begin{array}{c}\text { Living With } \\
\text { the Family }\end{array}$ & $\Sigma$ \\
\hline Living alone or in home care & 21 & 7 & 28 \\
Living with the family & 18 & 24 & 42 \\
$\Sigma$ & 39 & 31 & 70 \\
\hline
\end{tabular}

NOTE. $\chi^{2}=5.79 ; d f=1 ; P=1.61 \%$ (two-tailed).

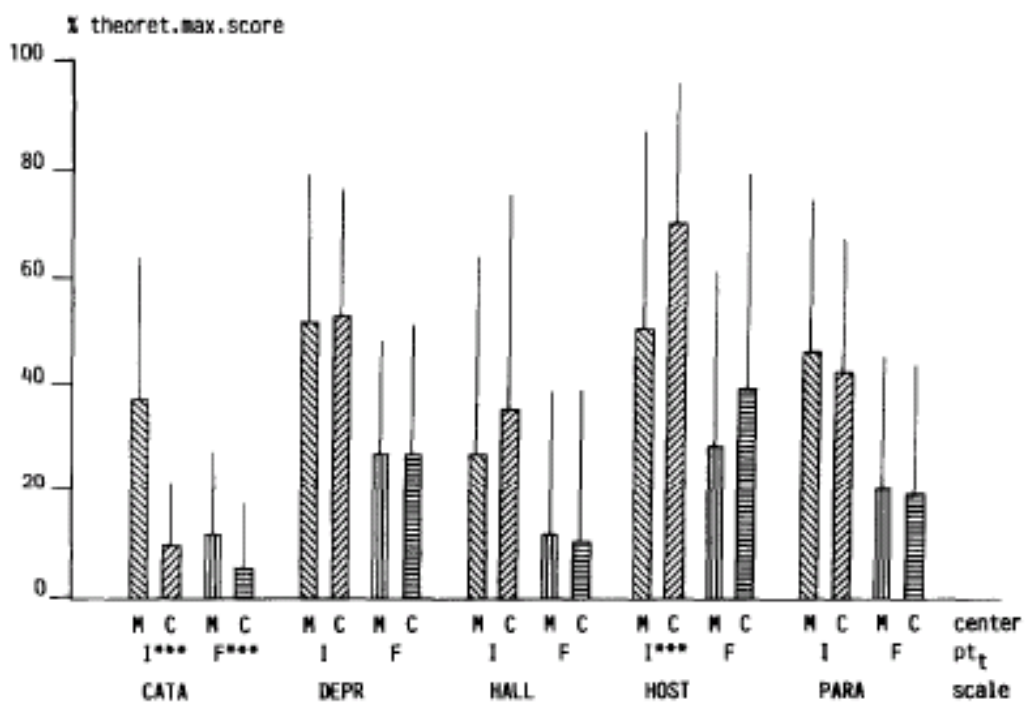

Fig 1. Means (oolumns) and standard deviations (lines) of the psychopathological scale values of the Munich (M) and the Cali (c) samples at index investigation (I) and follow-up

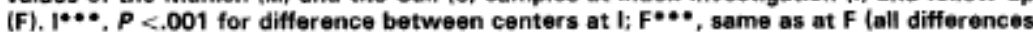
within centers between I and $F: P<.01$ to $P<.001$ ). $p$, point of time; CATA, cetatonic within centers between I and F: $P<.01$ to $P<.001$ ). pt, point of time; CATA, catatonic
symptoms; DEPR, depressive symptoms; HALL, hallucinatons; HOST, hostility: PARA, paranoid symptoms. 


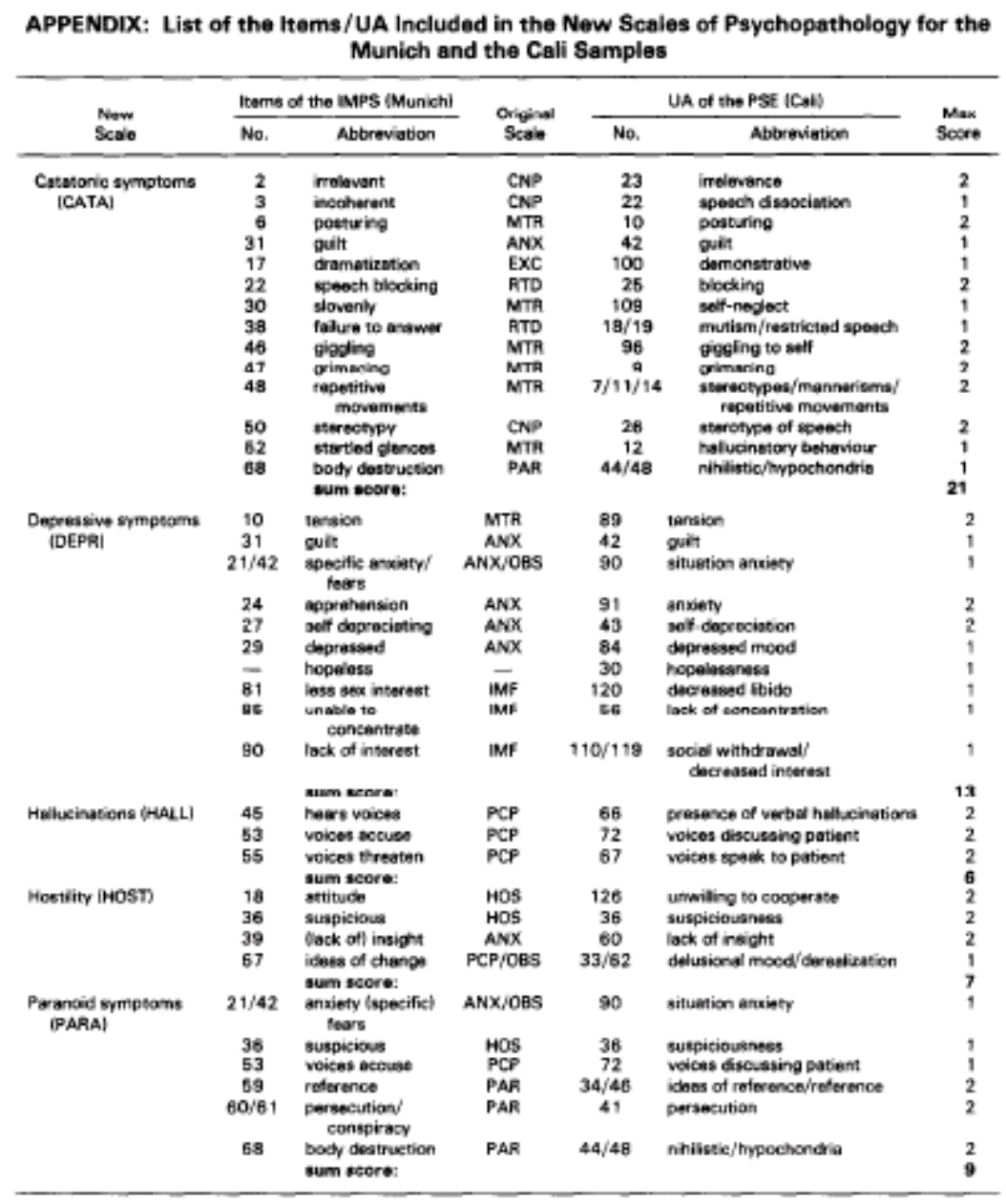

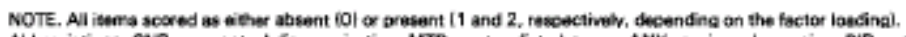

Abbrevigtions: CNP, conseptuel disorganization: MTR, motor disturbances; ANX, arcious depression; AID, reterdation and apsithr, PAP.

\section{References}

1. Westermeyer J: Psychosis in a peasant society: Social outcomes. Am J Psychiatry 137:1390-1394, 1980

2. World Health Organization: Report of the International Pilot Study of Schizophrenia, vol 1. Geneva, Switzerland, World Health Organization, 1973

3. World Health Organization: Schizophrenia: An International Follow-up Study. Chichester, UK. Wiley, 1979

4. Sartorius N, Jablensky A, Ernberg G, et al: Course of schizophrenia in different countries: Some results of a WHO international comparative 5-year follow-up study, in Häfner H, Gattaz WF, Janzarik W (eds): Search for the Causes of Schizophrenia. Berlin, FRG, Springer, 1987, pp 107-l 13

5. Möller H-J, Zerssen D von: Der Verlauf schizophrener Psychosen unter den gegenwärtigen Behandlungsbedingungen. Berlin, FRG, Springer, 1986

6. Möller H-J, Hohe-Schramm M, Cording-Tömmel C, et al: The classification of functional psychoses and its implications for prognosis. Br J Psychiatry 154:467-472, 1989

7. Strauss JS, Carpenter WT: The prediction of outcome in schizophrenia: I. Characteristics of outcome. Arch Gen Psychiatry 271739-746, 1972

8. Strauss JS, Carpenter WT: The prediction of outcome in schizophrenia: II. Relationships between predictor and outcome variables: A report from the WHO International Pilot Study of Schizophrenia. Arch Gen Psychiatry 3 1:37-42, 1974

9. Strauss JS, Carpenter WT: Prediction of outcome in schizophrenia: III. Five-year outcome and its predictors. Arch Gen Psychiatry 34:159-163, 1977 
10. Zerssen D von, Möller H-J: Prediction of outcome of schizophrenic psychosis: Prospective study based on five- to seven-year follow-up. Paper presented at the World Psychiatric Association Regional Meeting: Critical Issues in Psychiatry for the 80’s, New York, NY, 1981

11. León CA: Curso clinico y evolutión de la esquizofrenia en Cali: Un estudio de seguimiento a 10 años. Acta Psiquiatr Psicol Am Lat 32:95-136, 1988 (English version in press, J Nerv Ment Dis) 12. Spitzer RL, Endicott J, Robins E: Research Diagnostic Criteria: Rationale and reliability. Arch Gen Psychiatry 35:173-182, 1978

13. Kasanin J: The acute schizoaffective psychoses. Am J Psychiatry 90:97-126, 1933

14. Zerssen D von, Zaudig M, Cording C, et al: The predictive value of grouping schizoaffective psychoses together with affective psychoses: Jaspers' hierarchical rule revised, in Marneros A, Tsuang MT (eds): Schizoaffective and Affective Disorders: Similarities and Differences. Berlin, FRG, Springer, 1990, pp 33-52

15. Bleuler M: Die schizophrenen Geistesstörungen im Lichte langjähriger Kranken- und Familiengeschichten. Stuttgart, FRG, Thieme, 1972

16. Ciompi L, Müller C: Lebensweg und Alter der Schizophrenen. Berlin, FRG, Springer, 1976

17. Huber G, Gross G, Schüttler R: Schizophrenie. Berlin, FRG, Springer, 1979

18. Watt DC, Katz K, Shepherd M: The natural history of schizophrenia: A 5-year prospective followup of a representative sample of schizophrenics by means of a standardized clinical and social assessment. Psychol Med 13:663-670, 1983

19. Shepherd M, Watt D, Falloon I, et al: The National History of Schizophrenia. Cambridge, UK, Cambridge University, 1989

20. Lorr M, Klett CJ: Inpatient Multidimensional Psychiatric Scale (IMPS): Manual, revised. Palo Alto, CA, Consulting Psychologists, 1967

21. Wing JK, Cooper JE, Sartorius N: Measurement and Classification of Psychiatric Symptoms: An Instruction Manual for the PSE and Catego Program. Cambridge, UK, Cambridge University, 1974 22. Endicott J, Spitzer RL, Fleiss JL, et al: The global assessment scale: A procedure for measuring overall severity of psychiatric disturbance. Arch Gen Psychiatry 33:766-77 1, 1976

23. Goldstein MJ, Hand I, Hahlweg K: Treatment of Schizophrenia: Family Assessment and Intervention. Berlin, FRG, Springer, 1986

24. Held T: Psychiatrische Familienpflege: Ergebnisse einer prospektiven elfjährigen Langzeitstudie. Stuttgart, FRG, Enke, 1989

25. Hogarty GE, Anderson CM, Reiss DJ, et al: Family psychoeducation, social skills training, and maintenance chemotherapy in the aftercare treatment of schizophrenia: I. One-year effects of a controlled study on relapse and expressed emotion. Arch Gen Psychiatry 43:633-642, 1986 